\title{
Limits to gene flow in the slipper limpet Crepidula fornicata as revealed by microsatellite data and a larval dispersal model
}

\author{
Lise Dupont ${ }^{1,3}$, Céline Ellien $^{2}$, Frédérique Viard ${ }^{1, *}$ \\ ${ }^{1}$ Evolution \& Génétique des Populations Marines, UMR 7144 Adaptations et Diversité en Milieu Marin (CNRS-UPMC) \\ Station Biologique, Place Georges-Teissier, BP 74, 29682 Roscoff Cedex, France \\ ${ }^{2}$ UMR 5178 Biologie des Organismes Marins et Ecosystèmes (CNRS-UPMC-MNHN), Département Milieux et Peuplements \\ Aquatiques, Museum National d'Histoire Naturelle, 61 rue Buffon, 75231 Paris Cedex 5, France
}

${ }^{3}$ Present address: Laboratoire de Biologie des Sols et des Eaux, UMR 137 Biodiversité et fonctionnement des sols, Faculté des Sciences et Technologies, 61 avenue du Général de Gaulle, 94010 Créteil Cedex, France

\begin{abstract}
Crepidula fornicata, one of the most invasive marine sessile invertebrates in Europe, has traits commonly associated with a weak population genetic structure (high population connectivity): wide environmental tolerance, high fecundity, and a long planktonic larval stage (21 d). In order to determine the scale at which effective dispersal occurs in this potentially highly dispersive species, we designed a hierarchical sampling protocol and analyzed genetic variation at 4 microsatellite loci in 17 populations from 6 French bays situated in the English Channel and at the entrance of the English Channel (Iroise Sea). A strong regional pattern with populations clustered into 3 main groups (Iroise Sea, western and eastern English Channel) was revealed, as was significant isolation by distance along the Channel coasts. Conversely, a high degree of genetic connectivity was observed within the study bays. These estimates of effective dispersal were in agreement with outputs of a 2D larval-dispersal model based on local hydrodynamic conditions, suggesting that connectivity between populations of $C$. fornicata is influenced by hydrodynamic feature. This study suggests the existence of barriers to gene flow of C. fornicata over moderate distances (ca. $100 \mathrm{~km})$.
\end{abstract}

KEY WORDS: Slipper limpet · Larval dispersal $\cdot$ Invasive species · Gene flow · Dispersal modelling

\section{INTRODUCTION}

Pelagic larvae of benthic marine invertebrates are transported by oceanic currents for weeks to months, allowing for potential long-distance dispersal (Kinlan \& Gaines 2003). Dispersal drives species spread and population replenishment. Because the scale of dispersal has a strong influence at both ecological and evolutionary levels, it has been the focus of numerous empirical and theoretical studies (Levin 2006 and references therein). The rate and scale of successful exchanges (i.e. connectivity) among populations of marine organisms also have major implications in conservation biology - for instance, for the design of marine protected areas or for predicting the spread of invasive species (Kinlan \& Gaines 2003, Cowen et al. 2006).
In marine sessile invertebrates with pelagic larvae, an extended planktonic period is expected to be correlated with a high rate of larval exchange among populations, thus enhancing population connectivity over large distances (Kinlan \& Gaines 2003, Levin 2006). Populations of those species with a bentho-pelagic life cycle were thus first assumed to be demographically open, with recruitment originating mostly from distant sources (Caley et al. 1996), preventing the delineation of 'local populations' (as defined in Waples \& Gaggiotti 2006). This is summarized as the 'connectivity paradigm' by Levin (2006). The simple expectation of a correlation between long-distance dispersal ability (often based on the duration of the planktonic period) and effective (realized) dispersal is nevertheless largely debated. Recent works suggest that retention of larvae near their parental population is more frequent than 
suspected, and thus, that populations may be less open than originally thought (Levin 2006). Population genetic studies have indeed revealed limits to gene flow among conspecific marine populations without any obvious barriers to dispersal (e.g. Taylor \& Hellberg 2003). These limits were assumed to be promoted by biological factors (e.g. spawning season, settlement cues; Hohenlohe 2004) but also by physical processes such as ocean currents. Larvae may, for instance, be retained by nearshore circulation patterns, especially in estuaries or bays (McShane et al. 1988). Modeling of larval dispersal as a function of hydrodynamic processes has shown that, depending on water circulation conditions (e.g. tidal residual currents, wind-driven currents, eddies, and gyres), larvae can be either retained in the vicinity of adult populations, thus enabling local recruitment, or conversely be transported away from their parental population (e.g. Ellien et al. 2000, 2004, Hohenlohe 2004). Direct measurement of dispersal is a difficult task in the marine environment (Nathan 2001) and determining how far larvae tend to effectively disperse requires multiple approaches (Gilg \& Hilbish 2003, Hohenlohe 2004, Viard et al. 2006). Although still scarce, the joint analysis of realized dispersal (as measured by gene flow) and potential larval dispersal (based on realistic hydrodynamic models) is an efficient way to tackle this issue by balancing the caveats of each of these approaches (Thorrold et al. 2002, Kinlan \& Gaines 2003).

In the present study, we examined the connectivity paradigm in a potentially highly dispersive species, Crepidula fornicata, using complementary methods: (1) genetic analysis based on a hierarchical sampling design was carried out to estimate the effective dispersal (gene flow) at 2 spatial levels (within and among bays); and (2) a 2D hydrodynamic model was used to simulate the patterns of larval movement throughout the study area. The slipper limpet Crepidula fornicata provides an interesting case study, as the life-history traits of this gastropod are commonly associated with panmixia and weak genetic structure: it displays wide environmental tolerance (Blanchard 1997), efficient reproductive behavior (i.e. capacity of sex reversal and polyandry within mating groups; Dupont et al. 2006), high fecundity (Richard et al. 2006), and a long planktonic larval stage (3 to $4 \mathrm{wk}_{\text {; }}$ Coe 1949). Moreover, $C$. fornicata is a representative of one of the most invasive marine species introduced into Europe during the 20th century (Goulletquer et al. 2002). Native to western North Atlantic coasts, the slipper limpet has successfully colonized the coasts from Scandinavia to the Mediterranean Sea (Blanchard 1997). It was first recorded in Europe $>130$ yr ago (at the end of the 1870s in the UK; Blanchard 1997, Thielges 2005) and its first appearance along the French coasts of Brittany and Normandy occurred in the 1940s (Blanchard 1997). This species is now well established and its presence has major consequences for the indigenous macro-benthic fauna and their habitat (for review, see Thielges 2005). Over C. fornicata's native range in the USA, Collin (2001) identified 2 mitochondrial clades, but with only little geographic separation, as both clades were present in samples from the northernmost and southernmost populations, although at different frequencies. The lack of strong regional pattern in the native range prevented the identification of source populations using mtDNA (F. Viard, I. Kruse, D. McGlashan unpubl. data). Besides, previous genetic studies based on enzymatic loci (Hoagland 1985, Dupont et al. 2003) showed that the European populations of $C$. fornicata (including those located along the French coast of the English Channel) displayed genetic characteristics similar to those from populations in the native range of the species. Altogether, these genetic data and historical records (Blanchard 1997) support a scenario of introduction of the slipper limpet involving repeated introductions with no founder effects, a pattern commonly found in other gastropod species introduced in Europe (e.g. Cyclope neritea, Simon-Bouhet et al. 2006).

On finer scales, conflicting results have nevertheless been reported on the effective dispersal between populations of Crepidula fornicata along the French Atlantic and English Channel coasts. Based on 8 allozymic markers, Dupont et al. (2003) showed an unexpected significant genetic differentiation between Atlantic and English Channel populations. Conversely, only weak barriers to gene flow were observed on a fine scale, i.e. across a gulf located in the English Channel in which hydrodynamic processes like eddies may play a major role (Viard et al. 2006). Dupont et al. (2003) and Viard et al. (2006) exemplified the need to investigate different spatial ranges to determine the scale at which long-distance dispersal ability is effective. Limits to dispersal are indeed important determinants in biological invasion studies (Sakai et al. 2001).

In the present study, we investigated 17 samples of C. fornicata, hereafter referred to as localities, belonging to 5 French bays ( 2 to 4 localities per bay) located in the English Channel and 1 bay (Bay of Brest) at the entrance to the English Channel. Gene flow (effective dispersal) was estimated by performing a hierarchical analysis of the distribution of genetic diversity using 4 microsatellite loci. The high mutation rate of these markers allows us to trace back recent events and is much less influenced by historical features, compared to allozymes or mtDNA markers (Jarne \& Lagoda 1996). Because of its status as an introduced species, slipper limpet populations might not fulfill equilibrium assumptions used in tra- 
ditional population genetics model (e.g. F-statistics). We therefore used assignment methods and tests of equilibrium based on Bayesian and maximum likelihood approaches. These methods are useful to trace back and analyze contemporary events (Manel et al. 2005). The genetic structure that was revealed was then examined in light of the outputs of a 2D hydrodynamic model covering the study area (the English Channel) and simulating the patterns of larval transport according to local hydrodynamic conditions. The aims of this study were to determine: (1) whether a bay constitutes a spatial unit in which population connectivity is the rule (as previously observed in the St. Malo Gulf; Viard et al. 2006); (2) whether the disrupted distribution of $C$. fornicata in the English Channel (i.e. this species is mainly located in bays resulting in geographic discontinuity between dense populations) is strong enough to limit exchanges between bays despite the extended larval stage in this species; and (3) to what extent the limits to gene flow can be explained by hydrodynamic features.

\section{MATERIALS AND METHODS}

Sample collection and microsatellite genotyping. In order to examine the scale at which dispersal occurs on a regional scale in the slipper limpet Crepidula fornicata, a hierarchical sampling design was carried out. Adult individuals were collected in 6 bays situated on each part of the Cotentin peninsula in the English Channel (Fig. 1): the bays of Seine (Bs), Veys (Bv), Mont St. Michel (Bdm), St. Brieuc (Stb), Morlaix (Mx), and Brest (Br). Two to 4 localities per bay were sampled. The sampling methods and locations are indicated in Table 1. For $\mathrm{Bdm}$ and $\mathrm{Br}$, genotypes were obtained from Dupont et al. (2006), Viard et al. (2006), and Dupont et al. (2007). For all other localities, individuals were genotyped at 4 microsatellite loci: CfCA2, CfCA4, CfGT14, and CfH7, following protocols detailed in Dupont \& Viard (2003) and Viard et al. (2006). PCR products were screened on $6.5 \%$ polyacrylamide gel using a Li-COR NEN Global IR2 DNA sequencer system.
Statistical analyses of molecular data. Genetic diversity and test of equilibrium assumptions: For each locality, genetic diversity was analyzed by computing allele frequencies, number of alleles $\left(N_{\text {all }}\right)$, and expected heterozygozity $\left(H_{\mathrm{e}}\right)$ using GENETIX v. 4.05 (Belkhir et al. 2004). To take into account variation in sample size, allelic richness $\left(A_{\mathrm{r} i}\right.$ El Mousadik \& Petit 1996) was estimated using FSTAT v. 2.9.3, an updated version of v. 2.8 (Goudet 1999; available at http:// www2.unil.ch/popgen/softwares/fstat.htm). The null hypothesis of independence between loci was tested from statistical genotypic disequilibrium analysis using GENEPOP v. 3.4, an updated version of v. 1.2 (Raymond \& Rousset 1995; available at http://genepop.

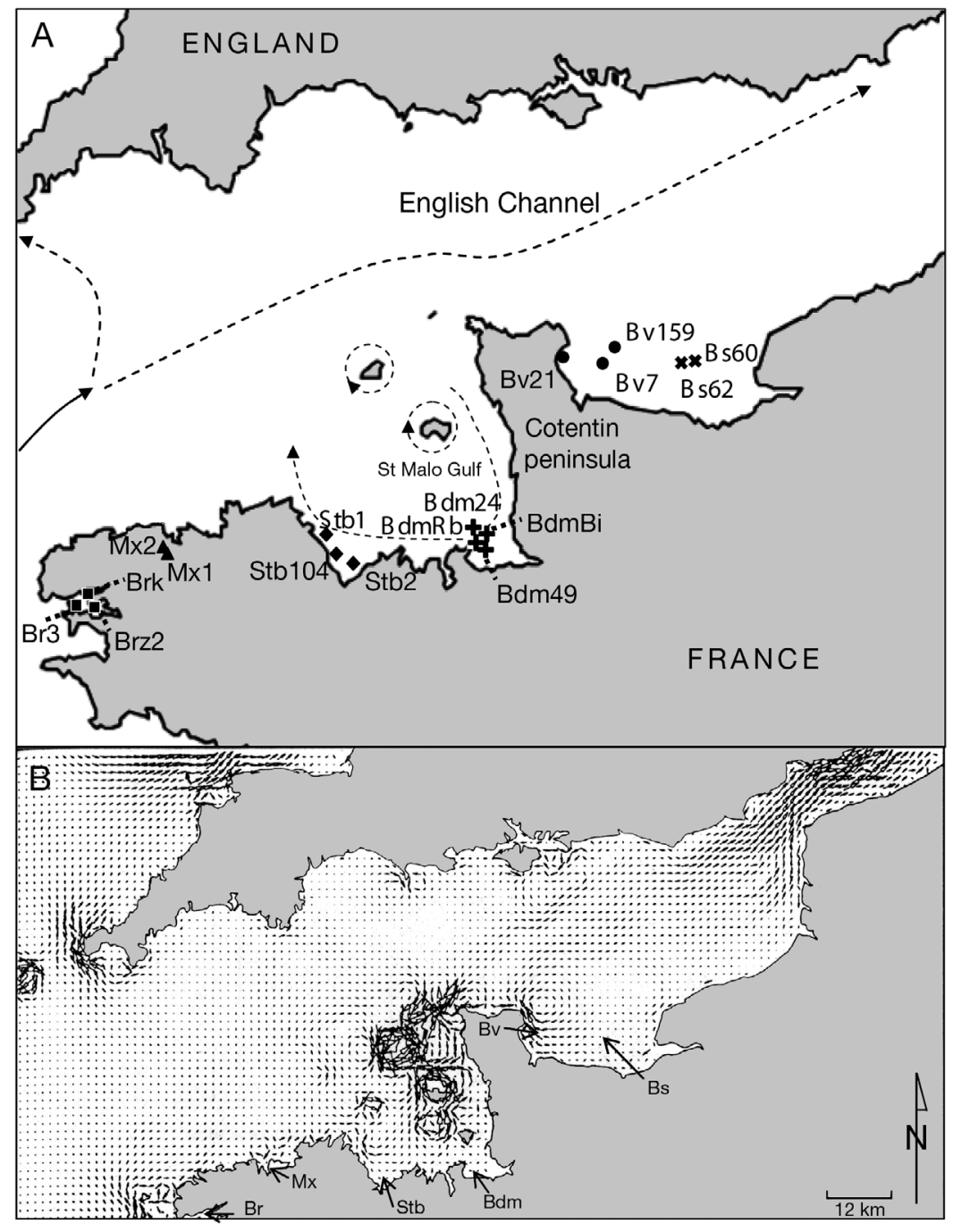

Fig. 1. Geographic and hydrodynamic characteristics of sampling locations. (A) Map of the 17 samples analyzed in the bays of Brest (Br, $\mathbf{\square})$, Morlaix $(\mathrm{Mx}, \mathbf{\Delta})$, St. Brieuc (Stb, $)$, Mont St. Michel $(\mathrm{Bdm}, \mathbf{+})$, Veys $(\mathrm{Bv}, \boldsymbol{\bullet})$, and Seine (Bs, $\boldsymbol{x})$. Arrows show long-term, average current trajectories (based on Salomon \& Breton 1993). (B) Residual Lagrangian velocity field for an average tide without wind, illustrating hydrodynamic currents (modified from Salomon \& Breton 1991) 
Table 1. Crepidula fornicata. Sampling characteristics and genetic diversity. $N_{\text {ind, }}$ sampling size for genetic analysis; $N_{\text {all }}$, number of alleles; $A_{\mathrm{r}}$, allelic richness; $H_{\mathrm{e}}$ gene diversity $( \pm \mathrm{SD}) ; \hat{f}$, heterozygote deficiency; $\mathrm{H}$. grab, Hamon grab. Within bays, these indices were calculated considering the bay as a single population. Permutation test of deviation from Hardy-Weinberg proportions: ${ }^{*} \mathrm{p}<0.05{ }^{* *} \mathrm{p}<0.01{ }^{* * *} \mathrm{p}<0.001$

\begin{tabular}{|c|c|c|c|c|c|c|c|c|c|}
\hline Bay & Pop. & Location & Method & Date & $N_{\text {ind }}$ & $N_{\text {all }}$ & $A_{\mathrm{r}}$ & $H_{\mathrm{e}}( \pm \mathrm{SD})$ & $\hat{f}$ \\
\hline \multirow[t]{3}{*}{ Seine } & Bs60 & $\begin{array}{l}49^{\circ} 31^{\prime} 88^{\prime \prime} \mathrm{N} \\
00^{\circ} 14^{\prime} 11^{\prime \prime} \mathrm{W}\end{array}$ & Dredging & 2001 & 40 & 14.2 & 12.5 & $0.796 \pm 0.204$ & $0.066^{\circ}$ \\
\hline & Bs62 & $\begin{array}{l}49^{\circ} 31^{\prime} 65^{\prime \prime} \mathrm{N} \\
00^{\circ} 16^{\prime} 97^{\prime \prime} \mathrm{W}\end{array}$ & Dredging & 2001 & 38 & 14.7 & 12.9 & $0.802 \pm 0.180$ & $0.092^{*}$ \\
\hline & Total & & & & 78 & 17.0 & 16.9 & $0.798 \pm 0.191$ & $0.078 *$ \\
\hline \multirow[t]{4}{*}{ Veys } & Bv159 & $\begin{array}{l}49^{\circ} 33^{\prime} 71^{\prime \prime} \mathrm{N} \\
00^{\circ} 54^{\prime} 90^{\prime \prime} \mathrm{W}\end{array}$ & Dredging & 2001 & 26 & 11.7 & 11.6 & $0.804 \pm 0.196$ & $0.223^{\cdots}$ \\
\hline & Bv7 & $\begin{array}{l}49^{\circ} 30^{\prime} 99^{\prime \prime} \mathrm{N} \\
00^{\circ} 59^{\prime} 64^{\prime \prime} \mathrm{W}\end{array}$ & Dredging & 2001 & 39 & 14.7 & 12.7 & $0.804 \pm 0.181$ & $0.112 *$ \\
\hline & Bv21 & $\begin{array}{l}49^{\circ} 32^{\prime} 00^{\prime \prime} \mathrm{N} \\
01^{\circ} 15^{\prime} 50^{\prime \prime} \mathrm{W}\end{array}$ & Dredging & 2003 & 41 & 13.7 & 12.0 & $0.756 \pm 0.251$ & 0.041 \\
\hline & Total & & & & 106 & 18.0 & 17.1 & $0.794 \pm 0.208$ & $0.122^{*}$ \\
\hline \multirow[t]{5}{*}{$\begin{array}{l}\text { Mont St. } \\
\text { Michel }\end{array}$} & $\mathrm{Bdm} 24$ & $\begin{array}{l}48^{\circ} 45^{\prime} 95^{\prime \prime} \mathrm{N} \\
01^{\circ} 50^{\prime} 10^{\prime \prime} \mathrm{W}\end{array}$ & H. grab & 2002 & 50 & 14.7 & 12.1 & $0.770 \pm 0.211$ & $0.047^{*}$ \\
\hline & BdmBi & $\begin{array}{l}48^{\circ} 45^{\prime} 05^{\prime \prime} \mathrm{N} \\
01^{\circ} 50^{\prime} 10^{\prime \prime} \mathrm{W}\end{array}$ & H. grab & 2002 & 56 & 16.5 & 12.6 & $0.768 \pm 0.242$ & $0.110^{\cdots}$ \\
\hline & BdmRb & $\begin{array}{l}48^{\circ} 43^{\prime} 25^{\prime \prime} \mathrm{N} \\
01^{\circ} 46^{\prime} 70^{\prime \prime} \mathrm{W}\end{array}$ & H. grab & 2002 & 52 & 17.5 & 13.1 & $0.761 \pm 0.238$ & $0.132^{\cdots}$ \\
\hline & Bdm49 & $\begin{array}{l}48^{\circ} 40^{\prime} 50^{\prime \prime} \mathrm{N} \\
01^{\circ} 45^{\prime} 50^{\prime \prime} \mathrm{W}\end{array}$ & H. grab & 2002 & 49 & 15.7 & 12.5 & $0.808 \pm 0.187$ & $0.138^{* *}$ \\
\hline & Total & & & & 207 & 22.5 & 18.1 & $0.778 \pm 0.221$ & $0.109 *$ \\
\hline \multirow[t]{4}{*}{ St. Brieuc } & Stb2 & $\begin{array}{l}48^{\circ} 35^{\prime} 00^{\prime \prime} \mathrm{N} \\
02^{\circ} 37^{\prime} 80^{\prime \prime} \mathrm{W}\end{array}$ & H. grab & 2002 & 31 & 14.5 & 13.3 & $0.806 \pm 0.204$ & $0.112 *$ \\
\hline & Stb104 & $\begin{array}{l}48^{\circ} 37^{\prime} 37^{\prime \prime} \mathrm{N} \\
02^{\circ} 45^{\prime} 41^{\prime \prime} \mathrm{W}\end{array}$ & H. grab & 2002 & 32 & 12.5 & 11.5 & $0.759 \pm 0.218$ & $0.124 "$ \\
\hline & Stb1 & $\begin{array}{l}48^{\circ} 42^{\prime} 62^{\prime \prime} \mathrm{N} \\
02^{\circ} 50^{\prime} 90^{\prime \prime} \mathrm{W}\end{array}$ & H. grab & 2002 & 31 & 13.0 & 12.0 & $0.780 \pm 0.186$ & $0.086^{*}$ \\
\hline & Total & & & & 94 & 19.2 & 18.5 & $0.784 \pm 0.203$ & $0.109 *$ \\
\hline \multirow[t]{3}{*}{ Morlaix } & Mx1 & $\begin{array}{l}48^{\circ} 40^{\prime} 20^{\prime \prime} \mathrm{N} \\
03^{\circ} 53^{\prime} 11^{\prime \prime} \mathrm{W}\end{array}$ & Diving & 2002 & 92 & 17.7 & 12.4 & $0.788 \pm 0.196$ & $0.086^{* *}$ \\
\hline & Mx2 & $\begin{array}{l}48^{\circ} 40^{\prime} 22^{\prime \prime} \mathrm{N} \\
03^{\circ} 53^{\prime} 17^{\prime \prime} \mathrm{W}\end{array}$ & Diving & 2002 & 78 & 19.2 & 13.1 & $0.792 \pm 0.199$ & $0.134^{* \cdots}$ \\
\hline & Total & & & & 170 & 21.7 & 18.4 & $0.790 \pm 0.197$ & $0.107^{*}$ \\
\hline \multirow[t]{4}{*}{ Brest } & Br3 & $\begin{array}{c}48^{\circ} 19^{\prime} 81^{\prime \prime} \mathrm{N} \\
04^{\circ \circ} 30^{\prime} 70^{\prime \prime} \mathrm{W}\end{array}$ & Dredging & 2003 & 86 & 12.2 & 9.3 & $0.777 \pm 0.134$ & $0.091^{*}$ \\
\hline & Brz2 & $\begin{array}{l}48^{\circ} 19^{\prime} 30^{\prime \prime} \mathrm{N} \\
04^{\circ} 31^{\prime} 70^{\prime \prime} \mathrm{W}\end{array}$ & Dredging & 2003 & 112 & 12.2 & 9.3 & $0.768 \pm 0.135$ & $0.076{ }^{\cdots}$ \\
\hline & Brk & $\begin{array}{l}48^{\circ} 22^{\prime} 33^{\prime \prime} \mathrm{N} \\
04^{\circ} 25^{\prime} 69^{\prime \prime} \mathrm{W}\end{array}$ & Dredging & 2003 & 87 & 11.7 & 9.2 & $0.773 \pm 0.136$ & $0.088^{* \cdots}$ \\
\hline & Total & & & & 287 & 14.7 & 12.0 & $0.772 \pm 0.136$ & $0.084 *$ \\
\hline TOTAL & & & & & 940 & 26.5 & & $0.790 \pm 0.186$ & $0.108^{* *}$ \\
\hline
\end{tabular}

curtin.edu.au). Tests for deviation from genotypic proportions expected under Hardy-Weinberg equilibrium (HWE) were based on randomization procedures implemented in FSTAT v. 2.9.3 programs. To adjust for multiple comparisons, control of the false discovery rate (FDR) was applied: q-values were computed using the QVALUE R package (Storey 2002). The method of Brookfield (1996) as implemented in the program MICRO-CHECKER (Van Oosterhout et al. 2004) was used to determine the most probable cause of deviation from HWE expectations. Null alleles are a common problem with microsatellite loci and can lead to artefactual heterozygote deficiencies (e.g. Astanei et al. 2005). Such heterozygote deficiency may also be due to preferential amplification of small alleles (i.e. large allele dropout or short allele dominance) or by slippage during PCR (Van Oosterhout et al. 2004). MICRO-CHECKER estimates the null allele frequency and adjusts the observed allele and genotype frequencies appropriately.

The presence of Crepidula fornicata was first recorded along the French coast of the English Channel $70 \mathrm{yr}$ ago, a short time scale relative to the time to reach population equilibrium. A previous study did not provide strong evidence for deviation from mutationdrift equilibrium in introduced slipper limpet popula- 
tions (Dupont et al. 2003). However, as different markers were used in Dupont et al. (2003), we tested for the hypothesis of deviation to mutation-drift equilibrium in the study populations by using the approach proposed by Cornuet \& Luikart (1996) and implemented in the software BOTTLENECK. Using a Wilcoxon test, the observed heterozygosity is compared with the heterozygosity expected under equilibrium considering a 2-phased mutational model (TPM) recommended for microsatellite data (Di Rienzo et al. 1994). Recently founded populations are expected to display a transient heterozygosity excess, whereas expanding populations (e.g. recovering from a bottleneck) should exhibit the opposite (Cornuet \& Luikart 1996). Then, departure from a migration-drift equilibrium was tested using a Bayesian approach developed by Ciofi et al. (1999) and implemented in the program 2MOD by M. A. Beaumont (available at www.rubic.rdg. ac.uk/ mab/software.html). The likelihoods of 2 models are compared: a model in which allele frequencies within a population are determined by a balance between drift and gene flow, and a model where allele frequencies are evolving purely through genetic drift. The method uses a Markov chain Monte Carlo (MCMC) simulation approach with Metropolis-Hastings sampling to explore the set of possible ancestral gene frequencies, alternative models (isolation vs. gene flow), and the likelihood of producing the observed data. The MCMC search was carried out twice for $10^{5}$ iterations, with the first $10 \%$ discarded to remove effects of initial starting parameters.

Genetic differentiation between localities: The genetic structure between localities or bays or group of bays was investigated by calculating $\hat{\theta}$ (Weir \& Cockerham 1984), an estimator of the fixation index $F_{\text {ST }}$ with FSTAT v. 2.9.3. Because samples were not in HWE, tests for genetic differentiation were carried out using a G-test (as described by Goudet et al. 1996) and implemented in FSTAT. To adjust for multiple comparisons, the FDR was applied: q-values were computed using the QVALUE R package (Storey 2002).

To illustrate the extent of spatial genetic variation among samples, a principal component analysis (PCA) was performed on allelic frequency data using PCAGEN 1.2 software (available at http://www2.unil.ch/ popgen/softwares/pcagen.htm). An $F_{\mathrm{ST}}$-based hierarchical analysis of molecular variance (AMOVA; Excoffier et al. 1992) was carried out to test for the regional structure of localities using Arlequin v. 3.1 (Excoffier et al. 2005): the genetic differentiation was investigated using a hierarchical analysis of the genetic variance by partitioning $\hat{\theta}$ into $\hat{\theta}_{\mathrm{w}}$ and $\hat{\theta}_{\mathrm{b}}$, indicating the genetic differentiation of samples within groups (e.g. within bays) and between groups (e.g. between bays), respectively. The level of significance of $\hat{\theta}_{\mathrm{w}}$ and $\hat{\theta}_{\mathrm{b}}$ was computed by non-parametric permutational procedures of genotypes among populations within groups and among populations between groups, respectively.

Alternative approaches to $F_{\mathrm{ST}}$-based methods, like assignment tests, have recently been proposed for gene flow inferences, especially for contemporary gene flow analyses and non-equilibrium situations (Manel et al. 2005) The overall low genetic structure and the limited number of loci used in our study prevented us from taking full advantage of these methods. However, for the sake of comparison with $F_{\mathrm{ST}}$-based analyses and, more specifically, to examine the hypothesis of genetic homogeneity at the level of a given bay, we carried out an assignment analysis using a Bayesian approach as described by Rannala \& Mountain (1997) and implemented in GeneClass v. 2.0 (Piry et al. 2004). We aimed to identify the relative proportion of individuals that were assigned to 1 locality external to the bay from where they were sampled. These individuals likely represent recent migrants, or individuals containing recently introgressed genomes.

2D hydrodynamic Lagrangian model of larval dispersal. We used a Lagrangian model to get a picture of the potential larval distribution (density and location of larvae) given hydrodynamic and climatic conditions following 1 episode of larval release from each of the study locations. Outputs of the model were summarized by building matrices of the number of larvae exchanged between each pair of populations. The hydrodynamic and larval transport models are detailed in Ellien et al. $(2000,2004)$ and the application to Crepidula fornicata is summarized in Viard et al. (2006). Briefly, this model, which simulates the transport of passive particles under the influence of a hydrodynamic regime dominated by tide and wind forces, is based on a hydrodynamic model for the English Channel, for which geographic limits are $48^{\circ} 18^{\prime} \mathrm{N}$ and $51^{\circ} 20^{\prime} \mathrm{N}$ in latitude, $6^{\circ} 28^{\prime} \mathrm{W}$ and $3^{\circ} 00^{\prime} \mathrm{E}$ in longitude, with a mesh size of 1 nautical mile (Salomon \& Breton 1991; Fig. 1B). Fourteen of the 17 study samples are within those limits (localities of Bs, Bv, Bdm, Stb, and $\mathrm{Mx}$ ), and the site of larval releases was chosen to fit exactly the location of each sample. The 2 localities in Mx were located in the same mesh and were therefore considered as a single site. In order to test the hypothesis of the isolation of the English Channel populations from the Atlantic, the model was also applied to a larval release at the entrance of the English Channel (Iroise Sea). C. fornicata is a perennial protandrous species with an extended breeding period from March to September (Richard et al. 2006). Biological inputs in the model were as follows. Larval dispersal was simulated over 21 d (i.e. larval lifespan) corresponding to the commonly accepted free-swimming period of the 
pelagic veligers of $C$. fornicata (Coe 1949). As we were only interested in the pattern of maximal diffusion of larvae and its relative differences among locations, the mortality term was set to zero. The same nonrestrictive amount of larvae $\left(10^{7}\right.$ larvae) was released in each locality. This number, based on biological data available in the literature, is representative of the amount of larvae released in a theoretical population with a density of 3400 ind. $\mathrm{m}^{-2}$ (i.e. a nonrestrictive density, greater than the densities recorded in the St. Malo Gulf where the highest densities were observed; Viard et al. 2006), a female:male ratio of 0.67:1 (Dupont et al. 2006, 2007), and an average fecundity of 7500 ovocytes per female (Richard et al. 2006). Larval dispersal was first studied considering an average tide and no wind influence. Then, further simulations were carried out with 2 types of wind-forcing, corresponding to the main wind directions influencing the study area: constant winds from SW (direction $225^{\circ}$ ) and NE (direction $45^{\circ}$ ) with a mean speed of $6 \mathrm{~m} \mathrm{~s}^{-1}$. Matrices of larval exchanges were built for each wind condition. Larval exchanges between populations A and B were defined as:

$$
\frac{L_{\mathrm{A} \rightarrow \mathrm{B}}}{\sum_{i} L_{i \rightarrow \mathrm{B}}+L_{\mathrm{B}}}+\frac{L_{\mathrm{B} \rightarrow \mathrm{A}}}{\sum_{i} L_{i \rightarrow \mathrm{A}}+L_{\mathrm{A}}}
$$

where $L_{i \rightarrow j}$ is the number of larvae transported from Population $i$ to Population $j$, and $L_{i}$ is the number of larvae retained in population $i$.

Correlation between genetic distance, geographic distance, and larval exchanges. To analyze the relationship between genetic distance $(\hat{\theta})$, coastline geographic distance $(\mathrm{km})$, and larval exchanges between localities (samples of the Bay of Brest are excluded, see the previous paragraph), Mantel tests were performed using GENEPOP v. 3.4. Mantel procedures can test for an association between 2 matrices using a randomization procedure. We tested for genetic isolation by geographic distance (Mantel 1967): coastline geographic distances $(\mathrm{km})$, measured from a map, were plotted against $\hat{\theta} /(1-\hat{\theta})$ to compute a linear relationship following the recommendations of Rousset (1997) to test for the null hypothesis of independence between genetic and geographic distances. Mantel tests were also used to test for the null hypothesis of independence between relative number of larvae exchanged among localities and geographic or genetic distances.

\section{RESULTS}

\section{Genetic diversity, HWE, and null alleles}

Exact tests for genotypic linkage disequilibrium between microsatellite loci within each locality showed only 2 significant $p$-values out of 102 pairwise comparisons. Across the 17 samples, no pair of loci was found to be in linkage disequilibrium. All 4 loci were polymorphic in all samples; the number of alleles per locus varied from 4 (CfCA2) to 61 (CfGT14) over the whole data set. Summary statistics describing the genetic diversity across loci within the 17 study samples are given in Table 1. Whatever the locality and over the whole data set, a high genetic diversity was observed. In the localities of the English Channel, the mean number of alleles per locus $\left(N_{\text {all }}\right)$ was found to vary depending on the sampling locality (from 11.7 to 19.2) but this was mainly due to a sampling size effect as shown by the value of the allelic richness $\left(A_{\mathrm{r}}\right)$, which was similar across sampling localities. The lowest values of $N_{\text {all }}$ were found in the Bay of Brest, and this was not only due to a sampling size effect, as the estimates of allelic richness in these samples were also the lowest values observed in the data set. These estimates were nevertheless not significantly different from those in other populations ( $t$-test; $\mathrm{p}>0.05$ ).

Significant departures from HWE were observed in 21 of 68 single-locus permutation tests after FDR correction. Following the method of Brookfield (1996) as implemented in the program MICROCHECKER, null alleles are likely to occur at low frequency at locus CA4 in 3 samples (BdmRb, frequency of null alleles $r=0.072$; $\mathrm{Bdm} 49, \mathrm{r}=0.078 ; \mathrm{StB} 2, \mathrm{r}=0.062)$, at locus $\mathrm{CfH7}$ in 1 sample (Bv159, $r=0.140)$, and at locus CfGT14 in all samples $(0.050<\mathrm{r}<0.247)$. There was no evidence for null alleles at locus CfCA2. In addition, evidence of stuttering was found for the locus CfGT14 in 2 samples (BdmBi, Mx2). Correcting the data for null alleles did not change the number of significant departures from HWE. This result may be explained by an incomplete recovery of null alleles due to size homoplasy (i.e. loss or gain of a variable number of repeat units that generates alleles identical in state but not in descent; Chapuis \& Estoup 2007). Another explanation is that departure from HWE is not due only to null alleles and technical artefacts. Apart from null alleles, heterozygote deficiencies at neutral loci can result from inbreeding or Wahlund effects. Paternity analyses (Dupont et al. 2006) carried out in the populations of the Bay of Brest (that are also investigated in the present study) did not reveal self-fertilization or assortative mating. In addition, heterozygote deficiencies are not congruent among loci, indicating that inbreeding is unlikely. Wahlund effects are also unlikely, as $F_{\mathrm{ST}}$ values are far lower than $F_{\text {IS }}$ (i.e. correlation of genes within individuals with respect to genes between individuals within populations) values (David et al. 1997). Moreover, Dupont et al. (2007) demonstrated a genetic homogeneity between cohorts within 2 populations of the Bay of Mont St. Michel, suggesting that temporal Wahlund does not occur. Thus, none of the above factors is 
clearly responsible alone for these departures from HWE explanations, but a combination of small additive effects of each of them might be the cause.

Outputs of the analyses carried out with the software BOTTLENECK did not provide any evidence of deviation from the mutation-drift equilibrium model in any of the samples tested under the TPM model, suggesting the absence of either recent expansion or recent bottleneck in the study localities. In addition, a Bayesian approach used to test for migration-drift equilibrium did not provide evidence of departure from this model: the pure-drift model was rejected in all simulations, and $100 \%$ of the simulated data points were consistent with the gene-flow-drift model.

\section{Genetic structure between localities within bays and over the whole data set}

Results for genetic structure between samples obtained with genotypic data both corrected and uncorrected for null alleles were generally similar. When different, results obtained with the corrected data set are presented in brackets. A significant genetic structure was revealed at the level of the whole study (17 samples, $\hat{\theta}=0.011, \mathrm{p}=0.002$ ) as well as at the level of the Channel only (i.e. excluding the Bay of Brest from the analysis; 14 samples, $\hat{\theta}=0.004, p=$ $0.002)$. When considering each locality pair, 66 values of $\hat{\theta}$ ( 76 with corrected data for null alleles) out of 136 ( $49 \%$ and $56 \%$, respectively) were associated with a significant G-test (Appendix 1). Fifty-seven were still significant after the FDR correction. These genetic differences between samples were not randomly distributed across the data set: a genetic homogeneity was generally observed within bays, whereas most of the significant genetic differences involved comparisons between localities from different bays. In particular, 42 out of $57(74 \%)$ of the significant $\hat{\theta}$ values after FDR correction involved pairwise comparisons between the samples of the Bay of Brest with all other samples (Appendix 1). The genetic isolation of the Bay of Brest is exemplified by the results of the principal components analysis based on allelic frequencies (PCA; Fig. 2). Within bays, only 2 comparisons out of $17(12 \%)$ revealed genetic differences between localities after FDR correction: significant values of $\hat{\theta}$ were detected within $\mathrm{Bv}$, between the localities Bv21 and Bv7 ( $\hat{\theta}=0.022, p$ $<0.001$ ) and within Stb, between the localities Stb1 and Stb104 $(\hat{\theta}=0.002$,

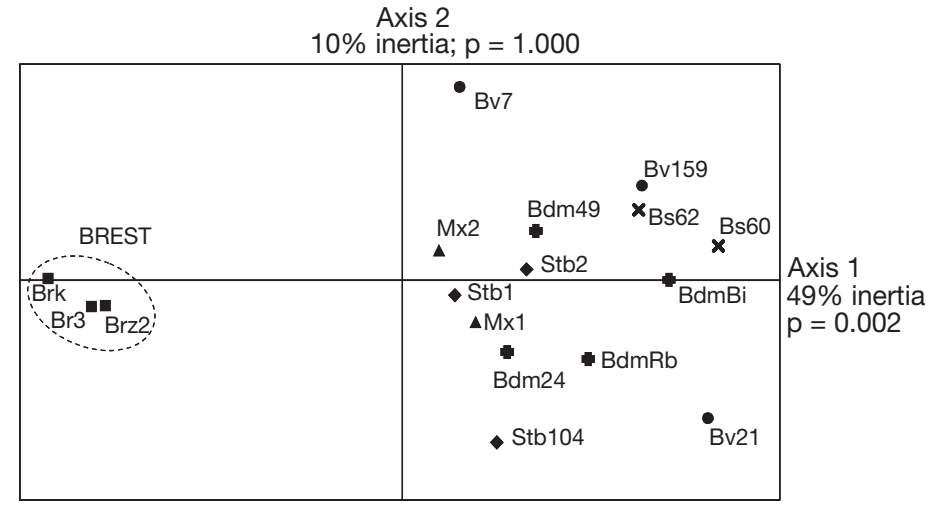

Fig. 2. Principal component analysis (PCA) performed using the allele frequencies of the 17 samples. Sampling locations as in Fig. 1

$\mathrm{p}<0.05$ ). Assignment tests revealed the same trend as $F_{\mathrm{ST}}$-based analyses: individuals tended to be assigned preferentially to a locality of the bay where they were sampled (Fig. 3). In only 1 locality (Mx1), individuals were assigned in a higher proportion to another bay $(22 \% ; \mathrm{Br})$. In the other localities of the Channel, between 30 and $77 \%$ of individuals were assigned to a locality of the bay to which they belong. In the Bay of Brest, 72 to $77 \%$ of the individuals were assigned to their bay of origin.

To test the hypothesis of a regional structure, a hierarchical analysis of the distribution of the genetic diversity (AMOVA) was done (Table 2). First, the genetic differentiation between 5 groups featuring the 5 bays (Bs, Bv, Bdm, Stb, and Mx) was computed. No significant genetic heterogeneity was observed when the 5 bays were considered separately (genetic differentiation of populations between groups, $\hat{\theta}_{\mathrm{b}}=0.001$, $\mathrm{p}=0.225$ ), whereas the genetic differences between localities over the whole data set or within bays were significant. Second, regional patterns were tested by merging populations from neighboring bays within a

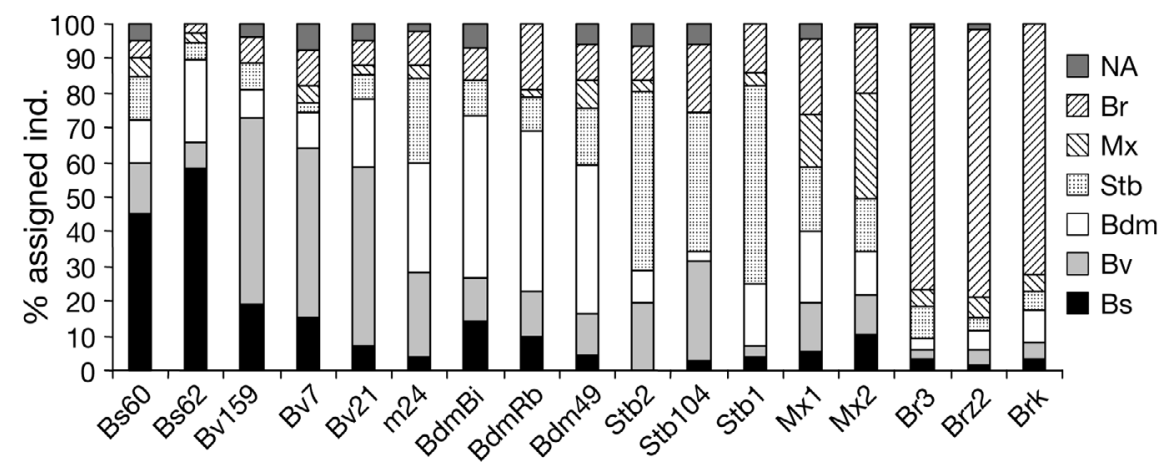

Fig. 3. Proportion of individuals assigned to each locality (assignment tests, GeneClass software). NA: individuals that could not be assigned ( $p<0.05)$. Sampling locations as in Fig. 1 
Table 2. Crepidula fornicata. AMOVA. $\hat{\theta}_{\mathrm{b}}, \hat{\theta}_{\mathrm{w}}, \hat{\theta}_{\mathrm{t}}$ : genetic differentiation between groups, between localities within groups, and between localities over the whole data set (regardless of the grouping), respectively. Bold: significant. Parentheses: results obtained from the corrected dataset for null alleles

\begin{tabular}{|lcc|}
\hline Grouping & Fixation index & $\mathrm{p}$ \\
\hline 5 groups: Bs, Bv, & & \\
Bdm, Stb, and Mx & & \\
$\hat{\theta}_{\mathrm{b}}$ & 0.001 & $0.225(0.272)$ \\
$\hat{\theta}_{\mathrm{w}}$ & $\mathbf{0 . 0 0 4}(\mathbf{0 . 0 0 5})$ & $0.021(0.003)$ \\
$\hat{\theta}_{\mathrm{t}}$ & $\mathbf{0 . 0 0 5}$ & $0.004(0.001)$ \\
2 groups: (1) Mx + & & \\
Stb and (2) Bs $+\mathrm{Bv}$ & & \\
$\hat{\theta}_{\mathrm{b}}$ & $\mathbf{0 . 0 0 3}(0.002)$ & $0.010(0.014)$ \\
$\hat{\theta}_{\mathrm{w}}$ & $0.003(\mathbf{0 . 0 0 5})$ & $0.116(0.006)$ \\
$\hat{\theta}_{\mathrm{t}}$ & $\mathbf{0 . 0 0 6}(\mathbf{0 . 0 0 7})$ & $0.006(0.001)$ \\
2 groups: (1) Mx + Stb & & \\
+ Bdm and (2) Bs + Bv & $\mathbf{0 . 0 0 2}$ & $0.004(0.014)$ \\
$\hat{\theta}_{\mathrm{b}}$ & $\mathbf{0 . 0 0 3 ( \mathbf { 0 . 0 0 4 } )}$ & $0.026(0.001)$ \\
$\hat{\theta}_{\mathrm{w}}$ & $\mathbf{0 . 0 0 5}(\mathbf{0 . 0 0 6})$ & $0.004(0.001)$ \\
$\hat{\theta}_{\mathrm{t}}$ & & \\
2 groups: $(1) \mathrm{Mx}+\mathrm{Stb}$ & & \\
and (2) Bs $+\mathrm{Bv}+\mathrm{Bdm}$ & 0.001 & $0.053(0.051)$ \\
$\hat{\theta}_{\mathrm{b}}$ & $\mathbf{0 . 0 0 3 ( \mathbf { 0 . 0 0 4 } )}$ & $0.012(0.001)$ \\
$\hat{\theta}_{\mathrm{w}}$ & $\mathbf{0 . 0 0 5}(\mathbf{0 . 0 0 6})$ & $0.004(0.001)$ \\
$\hat{\theta}_{\mathrm{t}}$ & & \\
\hline
\end{tabular}

single group. The $[\mathrm{Mx}+\mathrm{StB}]$ group differed significantly from the $[\mathrm{Bs}+\mathrm{Bv}]$ group $\left(\hat{\theta}_{\mathrm{b}}=0.003, \mathrm{p}=0.010\right)$, showing that the western and the eastern Channel groups are 2 entities that are genetically differentiated. In addition, the $[\mathrm{Mx}+\mathrm{StB}+\mathrm{Bdm}]$ group differed significantly from the $[\mathrm{Bs}+\mathrm{Bv}]$ group $\left(\hat{\theta}_{\mathrm{b}}=0.002, \mathrm{p}=\right.$ $0.004)$. The fixation index between the $[\mathrm{Mx}+\mathrm{StB}]$ and $[\mathrm{Bs}+\mathrm{Bv}+\mathrm{Bdm}]$ groups was the lowest and was marginally significant $\left(\hat{\theta}_{\mathrm{b}}=0.001, \mathrm{p}=0.053\right)$. The AMOVA results thus suggested that $\mathrm{Bdm}$, although intermediate, is closer to the western Channel (Mx and $\mathrm{StB}$ ) than to the eastern Channel (Bs and Bv) group.

\section{Larval dispersal modeling, gene flow estimates, and geographic distances}

The outputs of larval-dispersal modeling are summarized in Fig. 4. Whatever the wind conditions, after $21 \mathrm{~d}$, we found no exchange of larvae between bays, except between Bs and Bv with a NE wind (Fig. 4A). In particular, no larva released from the Iroise Sea could enter the English Channel. Within bays, 2 different patterns were observed. Within Bdm, the larvae released for any given source locality were found to be roughly randomly dispersed over the other localities of $\mathrm{Bdm}$, indicating that the different pools of larvae are well mixed within the bay, whatever the wind condi- tion. A different picture was observed in the other bays where some localities received more larvae than others. For example, larvae released from Bv7 or Bv21 were mostly transported to Bv159. In addition, the locality Bv21 received very few larvae (in total $<30 \%$ ) from any locality of $\mathrm{Bs}$ or $\mathrm{Bv}$ and even no larva at all with a NE wind. Moreover, larvae released from Bv21 were not retained in Bv21. In Stb, the large majority of larvae released from Stb1 or Stb104 were retained in the source locality. Conversely, larvae released from Stb2, although partly retained in their source locality, were also dispersed towards Stb1 and Stb104.

We used Mantel tests to investigate the overall relationships between genetic distances, geographic distances, and rate of larvae exchanged between localities of the English Channel (i.e. 13 localities, Mx2 pooled with $\mathrm{Mx} 1$ since they belong to the same mesh). There was a significant correlation between genetic differentiation and geographic distance (i.e. isolation by distance pattern), where geographic distance explained $18.4 \%$ of the genetic difference $(p=0.005)$. In addition, geographic distance was strongly negatively correlated with relative larval exchanges, whatever the wind condition $(\mathrm{r}=-0.762,-0.773$, and $-0.740, \mathrm{p}<0.001$, with no wind, SW wind, and NE wind, respectively). A slight negative correlation was observed between larval exchange and genetic distance $(\mathrm{r}=-0.030,-0.007$, and -0.041 , with no wind, SW wind, and NE wind, respectively). However, the correlation was only significant at the $10 \%$ threshold with a SW wind $(p=0.095)$ and not significant with no wind $(p=0.283)$ or a NE wind $(p=$ 0.219). Altogether, these Mantel tests showed that genetic data was in agreement with coastline geographic distances and larval movements.

\section{DISCUSSION}

Crepidula fornicata's characteristics (i.e. longdistance dispersal ability, wide environmental tolerance, and widespread distribution along the English Channel coasts) make it an ideal species for testing the relationship between long-distance dispersal ability and population connectivity (realized dispersal) and for examining multi-spatial scale genetic structure. Analyzing effective dispersal is a critical point for this exotic species. The spread of a non-native species in its introduction range is a key issue in invasion biology (Sakai et al. 2001).

\section{Realized dispersal}

The genetic study that we carried out on 17 populations of Crepidula fornicata located along the English 

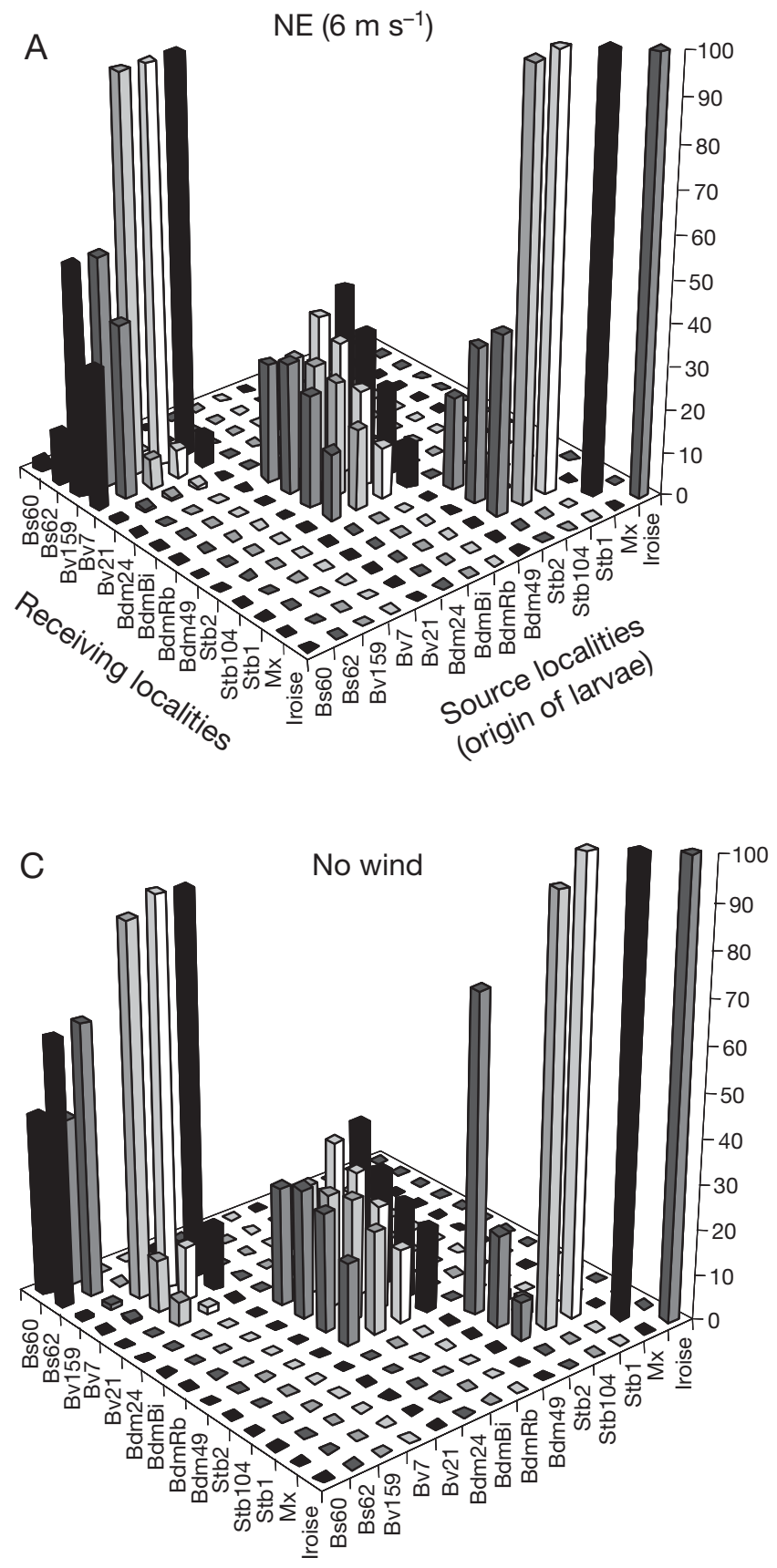

Channel coasts showed a relatively low level of differentiation among localities $\left(-0.003<F_{\mathrm{ST}}<0.039\right.$, Appendix 1). The present study's $F_{\mathrm{ST} \text {-estimate values }}$ are in accordance with those reported for other marine invertebrates with potentially high gene flow and found over similar geographic scales (e.g. $0.001<F_{\mathrm{ST}}<$ 0.043 in Callichirus islagrande, Bilodeau et al. 2005) or larger geographic scale (e.g. $-0.0001<F_{\mathrm{ST}}<0.061$ in Placopecten magellicanus, Kenchington et al. 2006). However, the overall genetic variation was not found to be randomly distributed across localities, and

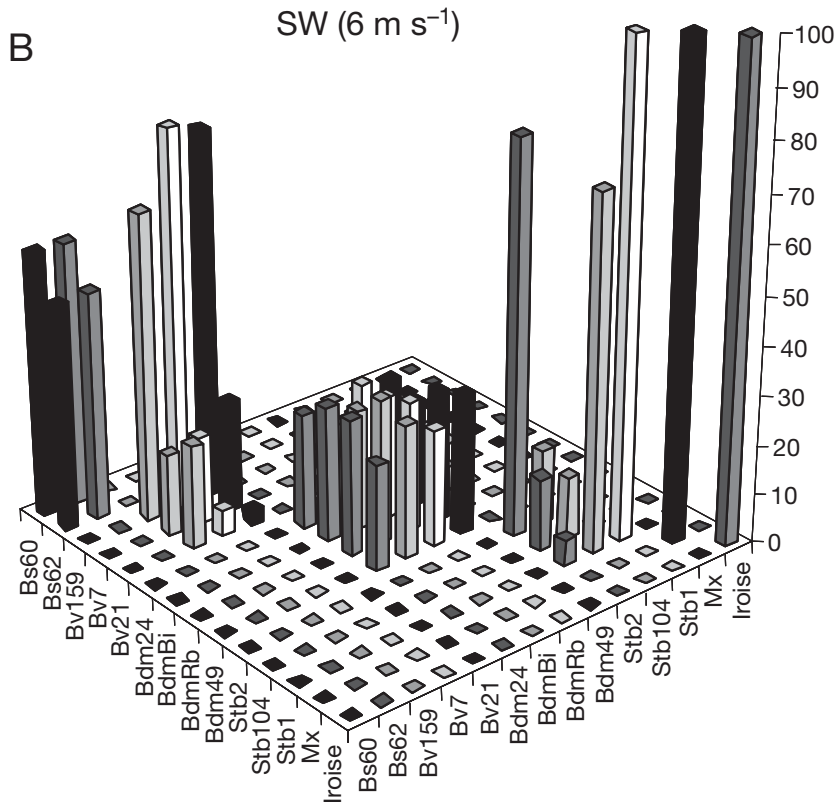

Fig. 4. Larval dispersal modelling outputs showing relative distribution of larvae in each locality (excluding Bay of Brest) after $21 \mathrm{~d}$ for (A) NE wind, (B) SW wind, (C) no wind. The total number of larvae that recruited to each locality was used to calculate the percentage of larvae that are migrants (i.e. arriving to 1 of the 14 potential receiver localities) or retained (i.e. not dispersed). Sampling locations as in Fig. 1. Shading added to differentiate between populations

genetic differences were found over distances of $120 \mathrm{~km}$ (e.g. Bay of Brest vs. Bay of Morlaix) or less (e.g. $<20 \mathrm{~km}$ apart between Bv7 and Bv21). Discrepancies between the potential for long-distance dispersal and the realized dispersal of marine invertebrates have been frequently reported in the literature (Kinlan \& Gaines 2003; Levin 2006 and references therein). An explanation for such apparently conflicting results is that nearshore circulation patterns may be affected by shoreline irregularities such as estuaries or bays, resulting in eddies and front that may retain larvae (McShane et al. 1988).

Within bays, at a fine-spatial scale, the connectivity between localities appeared to be the rule: high genetic similarity suggests a degree of gene flow between localities in all of the study bays. This pattern was confirmed by the output of the assignment test. This largely corroborates the results of Viard et al. (2006), who analyzed gene flow between 16 samples distributed in the Gulf of St. Malo, including the samples analyzed in the present study in the Bay of Mont St. Michel: only weak barriers to gene flow were found across the gulf despite a strong tidal regime and the action of wind-induced currents. Within the new study bays (Seine, Veys, St. Brieuc, Morlaix, and Brest), longdistance dispersal ability is thus also correlated with a 
large realized dispersal. Based on these results, a bay seems to be a relevant spatial unit for a population, defined in the ecological paradigm of Waples \& Gaggiotti (2006) as: 'a group of individuals which co-occur in space and time and have an opportunity to interact with each other' (here through larval dispersal and recruitment). In 2 bays (Veys and St. Brieuc), we nevertheless observed more confused patterns, with local genetic differentiation, as discussed in the next section.

In contrast to the large genetic homogeneity found at the single-bay level, our study also demonstrated that significant genetic differentiation occurs between bays. In particular, a strong genetic isolation of the localities from the Bay of Brest was shown. This was not observed by Dupont et al. (2003), who used weakly polymorphic allozyme markers on samples collected from this bay. Indeed, although they reported an $F_{\mathrm{ST}}$ value between the localities of Brest and St. Brieuc $\left(F_{\mathrm{ST}}\right.$ $=0.013)$ similar to that in the present study $\left(0.010<F_{\mathrm{ST}}\right.$ $<0.018,9$ pairwise comparisons), a much lower $F_{\mathrm{ST}}$ was shown between Morlaix and Brest (their $F_{\mathrm{ST}}=0.007 \mathrm{vs}$. our $0.011<F_{\mathrm{ST}}<0.015,6$ pairwise comparisons). The relative isolation of the Bay of Brest is in agreement with the characteristics of the bay: a semi-enclosed marine ecosystem (Richard et al. 2006) favorable to the isolation of the larval pool and, in the long term, genetic isolation. Thus, in the absence of gene flow, populations might have diverged from populations of the English Channel as a result of genetic drift, a hypothesis supported by the lower number of alleles in the samples of this bay compared to the other study localities. Besides the specific case of Brest, a strong hierarchical structure was shown along the English Channel coasts, revealing 2 groups located on both sides of the Cotentin Peninsula: a western and an eastern group. That the Cotentin peninsula may limit gene flow between the eastern and western areas of the English Channel has already been suggested by Dupont et al. (2003), who found that populations from the western English Channel were genetically differentiated from populations located in more northeastern locations than Bay of Veys and Bay of Seine. However, we also showed that the Cotentin Peninsula is not an impenetrable barrier to gene flow, since the population of the Bay of Mont St. Michel holds an intermediate position, although genetically closer to the western than to the eastern group, and might act as a supply source of larvae for both sides of the Cotentin Peninsula.

Besides biotic factors (e.g. larval duration) or abiotic processes (e.g. hydrodynamic features), the invasion process might be an alternative explanation for the differentiation between bays. Invasive species may indeed represent a challenge for population genetics studies, as introduced populations may retain genetic characteristics associated with the source population within the native range and can exhibit strong deviation from equilibrium assumptions, for instance because of strong founding events (Sakai et al. 2001). Multiple introductions of the slipper limpet along these study coasts might thus have originated from genetically differentiated sources (i.e. in relation to genetic structure in the native range) or major founder events may have occurred during each introduction process (i.e. successive founder effects enhancing the genetic differentiation between founding populations). However, several points make it unlikely that the invasion process alone could explain the observed genetic differentiation between bays. Firstly, a phylogenetic analysis of mitochondrial sequences from American samples of Crepidula fornicata revealed 2 distinct clades, indicating genetic differences among native US populations (Collin 2001). However, these genetic differences did not translate into a regional clustering of mitochondrial haplotypes of the 2 clades. Indeed, both clades were composed of northern and southern individuals, although at different frequencies. With a genetic structure not clearly related to the spatial distribution of the populations, different introduction processes from distinct spatial origins will be unlikely to translate into significant geographic genetic differences in the introduction area. Major founding effects are also unlikely. Indeed, Hoagland (1985) and Dupont et al. (2003) showed a similar level of genetic diversity at enzymatic loci between introduced and native populations. This was also confirmed with mtDNA data (F. Viard, I. Kruse, D. McGlashan unpubl.): both native and introduced populations were characterized by a high and comparable genetic diversity. Moreover, in the present study, no departure to mutation-drift equilibrium was found in the introduced localities. Finally, the results of $F_{\mathrm{ST}}$-based approaches were corroborated with outputs of the assignment tests that do not rely on equilibrium assumptions. This is in agreement with the temporal genetic stability observed in French populations of C. fornicata (Dupont et al. 2007). That equilibrium assumptions were not rejected and that outputs from different statistical methods (e.g. frequentist and Bayesian) were congruent suggests that the study populations might have reached equilibrium over a short time scale (ca. 100 to 200 generations with 1 to 2 generations $\mathrm{yr}^{-1}$ ), and thus that the effective population size is lower than suggested for many marine invertebrates (Palumbi 2003). Internal fertilization and biased sex ratio (due to protandry) are likely to decrease the effective size compared to an outbreeding and broadcast spawner (Turner et al. 2002). Estimation of effective size is a further step for understanding the contemporary dynamics of the slipper limpet. An alternative ex- 
planation is that the introduction might have occurred for much longer than the 70 years reported for its introduction in France, a point that would deserve further investigation, for instance by the analysis of preserved specimens (McGlashan et al. 2007).

The multispatial scale genetic analysis revealed a contrast between the genetic homogeneity within bays and the reduced gene flow between bays which is exemplified by the isolation by distance pattern found in the present study. Isolation by distance (IBD) may occur in subdivided populations, when subpopulations exchange genes at a rate dependent upon distance, or within a continuously distributed population, when dispersal of gametes and/or zygotes is spatially restricted (Hardy \& Vekemans 1999). IBD has been detected in coastal species with continuous distributions but usually over very large distances. For instance, a pattern of isolation by distance was reported in the coral Balanophyllia elegans (Hellberg 1994) and the abalone Haliotis rubra (Brown 1991) over geographic distances between 2500 and $3000 \mathrm{~km}$. In Crepidula fornicata, the pattern of IBD revealed that the location of the C. fornicata populations (mainly within bays) might restrict gene flow over a much smaller distance $(100 \mathrm{~km})$.

\section{Effect of hydrodynamic features on genetic structure}

Traditional population genetics provide information on the degree of gene flow between populations (Johnson \& Black 1995), but include historical effects (Slatkin \& Barton 1989) and generally (excluding assignment tests) do not precisely link 1 given source to 1 given receiving population for a given generation (Largier 2003). Thus, without data on larval exchange, an explanation of the observed genetic structure is incomplete. Because historical factors alone (i.e. invasion process) are unlikely to explain the observed genetic structure (see above), we here computed connectivity matrices and dispersal trajectories with a numerical model of larval dispersal to assess the extent to which effective (realized) dispersal is congruent with contemporary and potential larval diffusion. More specifically, we estimated the maximal distance of larval dispersal given the hydrodynamic conditions in order to test if genetic isolation might be explained by hydrodynamic features. The model predicted a high rate of larval retention within bays during 1 episode of larval discharge, which is consistent with the pattern of genetic isolation by geographic distance observed along the English Channel coasts: successive events of larval diffusion over a few years with a small number of migrants escaping their local natal populations is indeed compatible with such a pattern. Also, no larva released from the Iroise Sea could enter the English Channel, a result in agreement with the strong genetic differentiation observed between the Br localities and all the other bays. Despite an extended pelagic duration $(21 \mathrm{~d})$, gene flow appeared to be constrained even at a small spatial scale $(<50 \mathrm{~km}$; within bays $)$ in Crepidula fornicata. The mathematical modeling of larval dispersal suggested that this result may be largely explained by oceanographic mechanisms. Indeed, semi-enclosed bays are particularly effective at retaining water and plankton and reducing alongshore transport (Largier 2003). Moreover, larvae can be retained by eddies that may occur on different scales (from $>100 \mathrm{~km}$ to $\leq 1 \mathrm{~km}$, Largier 2003). Water recirculation in these eddies can retain larvae over time scales comparable with dispersal duration, and thus may account for enhanced local recruitment at specific locations. Our results corroborate the simulations of Ophiothrix fragilis larval dispersal by Lefebvre et al. (2003), who showed that the occurrence of several permanent clockwise and counterclockwise eddies in the St. Malo Gulf (cf. Salomon \& Breton 1993) traps larvae for $3 \mathrm{wk}$ and longer. In the same way, simulations of Pectinaria koreni larval dispersal carried out by Ellien et al. (2000) showed that larvae released from the Bay of Veys are retained in the eddy off Barfleur, situated northeast of the Cotentin Peninsula. The presence of eddies on each part of the Cotentin peninsula may explain the limited gene flow between the western and eastern English Channel (Fig. 2). In contrast to the St. Malo Gulf eddies, which persist whatever the meteorological conditions (Lefebvre et al. 2003), the eddy off Barfleur disappears when NE wind speed exceeds $6 \mathrm{~m} \mathrm{~s}^{-1}$ and larvae are advected westwards, north of the Cotentin (Ellien et al. 2000). The barrier to gene flow created by this eddy might thus be permeable depending on wind conditions.

Local genetic isolation was observed in 2 bays: Bay of Veys and Bay of St. Brieuc. These specific cases of genetic isolation at the level of a given bay were congruent with the outputs of the hydrodynamic model of larval dispersal. For example, larvae released from Bv7 or Bv21 were mostly recruited in Bv159. In addition, the population Bv21 received very few larvae (in total $<30 \%$ ) from any Bs or Bv population, and even no larva at all with a NE wind. This is congruent with the particular genetic structure detected within the Bay of Veys: Bv7 and Bv21 were genetically differentiated but each was similar to Bv159 (Appendix 1). In the same way, larvae released from Stb2, although partly retained in their parental locality, were also dispersed towards Stb1 and Stb104. This result is again in agreement with the genetic results that showed no difference between Stb2 and Stb1 or Stb104 but significant differentiation between Stb1 and Stb104. 
Mathematical modeling of larval dispersal has been shown to explain patterns of genetic differentiation in other marine invertebrates, e.g. Mytilus edulis (Gilg \& Hilbish 2003) and Littorina sp. (Hohenlohe 2004). In their reviews, Hellberg et al. (2002) and Palumbi (2003) concluded that fish and invertebrate larval transport exerts its greatest influence on genetic structure at intermediate scales (ca. $100 \mathrm{~km}$ ). The congruence between the estimated genetic distances (i.e. $\hat{\theta} /[1-\hat{\theta}])$ and the simulation outputs for Crepidula fornicata showed in the present study at a medium scale (100 to $200 \mathrm{~km})$ fit well with these statements. Our results thus suggest that hydrodynamics might predict the general patterns of effective dispersal throughout the Channel in this species. However, we failed to obtain a significant correlation between the population pairwise matrices of genetic structure and larval exchanges. This might be due to the difference in the temporal scale of both analyses. Indeed, information from DNA passed through multiple generations, whereas simulations only showed events happening during the $21 \mathrm{~d}$ of dispersal. Extending this model to 3 dimensions and over multiple generations might more accurately test for the putative correlation between larval dispersal and gene flow in this species. In addition, despite the significant role of hydrodynamic mechanisms on larval retention, biological factors cannot be ignored. For instance, genetic differentiation within bays (e.g. Bv and Stb) might be explained by biological parameters that may limit gene flow, such as predation, selection on recently settled juveniles, demography, and fecundity (for review, see Hohenlohe 2004). A variety of larval behaviors may also be important. In particular, in sessile marine invertebrates, environmental stimuli that trigger larval settlement might also play a role in the retention of larvae near parental population. For instance, laboratory experiments of $C$. fornicata suggested that its aggregated distribution is the result of gregarious settlement in response to chemical cues released by conspecific adults (Pechenik \& Gee 1993). Although the retention of larvae within bays seems important, we also must not ignore that not all larvae are retained. If even a small fraction of these successfully recruit elsewhere, their contribution to connectivity may be significant.

Acknowledgements. The authors are grateful to E. Foucher, M. T. Jolly, J. Richard, M. Savina, G. Thouzeau, the crew of the RV 'Côte de la Manche', as well as the participants to the BENTHOMONT cruise and the scuba divers of 'Service Mer \& Observation' of Roscoff for help in collecting samples of Crepidula fornicata. The authors are also grateful to C. Daguin and T. Comtet for their stimulating comments and extensive reading of the manuscript. This project was funded by the PNEC-Site Atelier 'Baie du Mont St. Michel' and the
INVABIO program of the Ministère de l'Ecologie et du Développement Durable (project no. D4E/SRP/01115). Additional supports for genotyping came from the European Network of Excellence 'Marine Genomics'. L.D. acknowledges the Region Bretagne for her PhD grant.

\section{LITERATURE CITED}

Astanei I, Gosling E, Wilson J, Powell E (2005) Genetic variability and phylogeography of the invasive zebra mussel, Dreissena polymorpha (Pallas). Mol Ecol 14:1655-1666

Belkhir K, Borsa P, Goudet J, Chikhi L, Bonhomme F (2004) GENETIX 4.05, logiciel sous Windows pour la génétique des populations. Laboratoire Génome, Population, Interactions, Université Montpellier II

Bilodeau AL, Felder DL, Neigel JE (2005) Population structure at two geographic scales in the burrowing crustacean Callichirus islagrande (Decapoda, Thalassinidea). Evolution 59:151-164

Blanchard M (1997) Spread of the slipper limpet Crepidula fornicata (L. 1758) in Europe: current state and consequences. Sci Mar 61:109-118

Brookfield (1996) A simple new method for estimating null allele frequency from heterozygote deficiency. Mol Ecol 5:453-455

Brown LD (1991) Genetic variation and population structure in the blacklip abalone, Haliotis rubra. Aust J Mar Freshw Res 42:77-90

Caley MJ, Carr MH, Hixon MA, Hughes TP, Jones GP, Menge BA (1996) Recruitment and the local dynamics of open marine populations. Annu Rev Ecol Syst 27: $477-500$

Chapuis MP, Estoup A (2007) Microsatellite null alleles and estimation of population differentiation. Mol Biol Evol 24:621-631

Ciofi C, Beaumont MA, Swingland IR, Bruford MW (1999) Genetic divergence and units for conservation in the Komodo dragon Varanus komodoensis. Proc R Soc Lond 266:2269-2274

Coe WR (1949) Divergent methods of development in morphologically similar species of prosobranch gastropods. J Morphol 84:386-399

Collin R (2001) The effects of mode of development on phylogeography and population structure of North Atlantic Crepidula (Gastropoda: Calyptraeidae). Mol Ecol 10:2249-2262

Cornuet JM, Luikart G (1996) Description and power analysis of two tests for detecting recent population bottlenecks from allele frequency data. Genetics 144:2001-2014

Cowen RK, Paris CB, Srinivasan A (2006) Scaling of connectivity in marine populations. Science 311:522-527

David P, Perdieu MA, Pernot AF, Jarne P (1997) Fine-grained spatial and temporal population structure in the marine bivalve Spisula ovalis. Evolution 51:1318-1322

Di Rienzo A, Peterson AC, Garcza JC, Valdes AM, Slatkin M, Freimer NB (1994) Mutational processes of simplesequence repeat loci in human populations. Proc Natl Acad Sci USA 91:3166-3170

Dupont L, Viard F (2003) Isolation and characterization of highly polymorphic microsatellite markers from the marine invasive species Crepidula fornicata (Gastropoda: Calyptraeidae). Mol Ecol Notes 3:498-500

Dupont L, Jollivet D, Viard F (2003) High genetic diversity and ephemeral drift effects in a successful introduced mollusc (Crepidula fornicata: Gastropoda). Mar Ecol Prog Ser 253:183-195 
Dupont L, Richard J, Paulet YM, Thouzeau G, Viard F (2006) Gregariousness and protandry promote reproductive insurance in the invasive gastropod Crepidula fornicata: evidence from assignment of larval paternity. Mol Ecol 15:3009-3021

Dupont L, Bernas D, Viard F (2007) Sex and genetic structure across age groups in populations of the European marine invasive mollusc, Crepidula fornicata L. (Gastropoda). Biol J Linn Soc 90:365-374

El Mousadik A, Petit RJ (1996) High level of genetic differentiation for allelic richness among populations of the argan tree [Argania spinosa (L.) Skeels] endemic to Morocco. Theor Appl Genet 92:832-839

Ellien C, Thiebaut E, Barnay AS, Dauvin JC, Gentil F, Salomon JC (2000) The influence of variability in larval dispersal on the dynamics of a marine metapopulation in the eastern Channel. Oceanol Acta 23:423-442

Ellien C, Thiebaut E, Dumas F, Salomon JC, Nival P (2004) A modelling study of the respective role of hydrodynamic processes and larval mortality on larval dispersal and recruitment of benthic invertebrates: example of Pectinaria koreni (Annelida: Polychaeta) in the Bay of Seine (English Channel). J Plankton Res 26:117-132

Excoffier L, Smouse P, Quattro J (1992) Analysis of molecular variance inferred from metric distances among DNA haplotypes: application to human mitochondrial DNA restriction data. Genetics 131:479-491

Excoffier L, Laval G, Schneider S (2005) Arlequin ver. 3.0: an integrated software package for population genetics data analysis. Evol Bioinformatics online 1:47-50

Gilg MR, Hilbish TJ (2003) The geography of marine larval dispersal: coupling genetics with fine-scale physical oceanography. Ecology 84:2989-2998

Goudet J (1999) FSTAT vers. 2.8, updated from Goudet (1995). Fstat: a computer program to calculate F-statistics. J Hered 86:485-486

Goudet J, Raymond M, De Meeüs T, Rousset F (1996) Testing differentiation in diploid populations. Genetics 144: 1933-1940

Goulletquer P, Bachelet G, Sauriau PG, Noel P (2002) Open Atlantic coast of Europe - a century of introduced species into French waters. In: Leppäkoski E, Gollash S, Olenin S (eds) Invasive aquatic species of Europe. Kluwer Academic Publishers, Dordrecht, The Netherlands, p 276-290

Hardy OJ, Vekemans X (1999) Isolation by distance in a continuous population: reconciliation between spatial autocorrelation analysis and population genetics models. Heredity 83:145-154

Hellberg ME (1994) Relationships between inferred levels of gene flow and geographic distance in a philopatric coral Balanophyllia elegans. Evolution 48:1829-1854

Hellberg ME, Burton RS, Neigel JE, Palumbi SR (2002) Genetic assessment of connectivity among marine populations. Bull Mar Sci 70:S273-S290

Hoagland KE (1985) Genetic relationships between one British and several North American populations of Crepidula fornicata based on allozymes studies (Gastropoda: Calyptraeidae). J Mollusc Stud 51:177-182

Hohenlohe PA (2004) Limits to gene flow in marine animals with planktonic larvae: models of Littorina species around Point Conception, California. Biol J Linn Soc 82: 169-187

Jarne P, Lagoda JL (1996) Microsatellites, from molecules to populations and back. Trends Ecol Evol 11:424-429

Johnson MS, Black R (1995) Neighbourhood size and the importance of barriers to gene flow in an intertidal snail.
Heredity 75:142-154

Kenchington EL, Patwary MU, Zouros E, Bird CJ (2006) Genetic differentiation in relation to marine landscape in a broadscape-spawning bivalve mollusc (Placopecten magellanicus). Mol Ecol 15:1781-1796

Kinlan BP, Gaines SD (2003) Propagule dispersal in marine and terrestrial environments: a community perspective. Ecology 84:2007-2020

Largier JL (2003) Considerations in estimating larval dispersal distances from oceanographic data. Ecol Appl 13:S71-S89

Lefebvre A, Ellien C, Davoult D, Thiébault E, Salomon JC (2003) Pelagic dispersal of the brittle-star Ophiothrix fragilis larvae in a megatidal area (English Channel, France) examined using an advection/diffusion model. Estuar Coast Shelf Sci 57:421-433

Levin LA (2006) Recent progress in understanding larval dispersal: new directions and digressions. Integr Comp Biol 46:282-297

Manel S, Gaggiotti OE, Waples RS (2005) Assignment methods: matching biological questions with appropriate techniques. Trends Ecol Evol 20:136-142

Mantel N (1967) The detection of disease clustering and a generalized regression approach. Cancer Res 27: 209-220

McGlashan DJ, Ponniah M, Cassey P, Viard F (2007) Clarifying marine invasions with molecular markers: an illustration based on mtDNA from mistaken calyptraeid gastropod identifications. Biol Invasions, doi: 10.1007/ s10530-007-9106-0

McShane PE, Black KP, Smith MG (1988) Recruitment processes in Haliotis rubra (Mollusca: Gastropoda) and regional hydrodynamics in southeastern Australia imply localized dispersal of larvae. J Exp Mar Biol Ecol 124:175-203

Nathan R (2001) The challenges of studying dispersal. Trends Ecol Evol 16:481-483

Palumbi SR (2003) Population genetics, demographic connectivity, and the design of marine reserves. Ecol Appl 13:S146-S158

Pechenik JA, Gee CC (1993) Onset of metamorphic competence in larvae of the gastropod Crepidula fornicata (L.) judged by a natural and artificial cue. J Exp Mar Biol Ecol 167:59-72

Piry S, Alapetite A, Cornuet JM, Paetkau D, Baudouin L, Estoup A (2004) GeneClass2: a software for genetic assignment and first-generation migrant detection. J Hered 95:536-539

Rannala B, Mountain JL (1997) Detecting immigration by using multilocus genotypes. Proc Natl Acad Sci USA 94:9197-9201

Raymond M, Rousset F (1995) GENEPOP (version 1.2): population genetics software for exact tests and ecumenicism. J Hered 86:248-249

Richard J, Huet M, Thouzeau G, Paulet YM (2006) Reproduction of the invasive slipper limpet, Crepidula fornicata, in the Bay of Brest, France. Mar Biol 149:789-801

Rousset F (1997) Genetic differentiation and estimation of gene flow from F-statistics under isolation by distance. Genetics 145:1219-1228

Sakai AK, Allendorf FW, Holt JS, Lodge DM and 11 others (2001) The population biology of invasive species. Ann Rev Ecol Syst 32:305-332

Salomon JC, Breton M (1991) Courants résiduels de marée dans la Manche. Oceanol Acta 11:47-53

Salomon JC, Breton M (1993) An atlas of long-term currents in the Channel. Oceanol Acta 16:439-448 
Simon-Bouhet B, Garcia-Meunier P, Viard F (2006) Multiple introductions promote range expansion of the mollusc Cyclope neritea (Nassariidae) in France: evidence from mitochondrial sequence data. Mol Ecol 15:1699-1711

Slatkin M, Barton NH (1989) A comparison of three indirect methods for estimating average levels of gene flow. Evolution 43:1349-1368

Storey J (2002) A direct approach to false discovery rates. J R Stat Soc B 64:479-498.

Taylor MS, Hellberg ME (2003) Genetic evidence for local retention of pelagic larvae in the Caribbean reef fish. Science 299:107-109

Thielges DW (2005) Impact of an invader: epizootic American slipper limpet Crepidula fornicata reduces survival and growth in European mussels. Mar Ecol Prog Ser 286:13-19

Thorrold S, Jones G, Hellberg M, Burton R, Swearer S, Neigel J, Morgan S, Warner R (2002) Quantifying larval retention and connectivity in marine populations with artificial and natural markers. Bull Mar Sci 70:291-308

Turner TF, Wares JP, Gold JR (2002) Genetic effective size is three orders of magnitude smaller than adult census size in an abundant, estuarine-dependent marine fish (Sciaenops ocellatus). Genetics 162:1329-1339

Van Oosterhout C, Hutchinson WF, Wills DPM, Shipley P (2004) MICRO-CHECKER: software for identifying and correcting genotyping errors in microsatellite data. Mol Ecol Notes 4:535-538

Viard F, Ellien C, Dupont L (2006) Dispersal ability and invasion success of Crepidula fornicata in a single gulf: insights from genetic markers and larval-dispersal models. Helgol Mar Res 60:144-152

Waples RS, Gaggiotti O (2006) What is a population? An empirical evaluation of some genetic methods for indentifying the number of gene pools and their degree of connectivity. Mol Ecol 15:1419-1439

Weir BS, Cockerham CC (1984) Estimating F-statistics for the analysis of population structure. Evolution 38:1358-1370

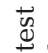
U⿺辶一

휼

营

象象

\&

○

츙

ปै

(⿻)

홍 훙

ฮิ

윰됴

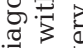

政

응

gi :

过

$\underset{0}{\square}$

敢

응

는

궁 क्ष

항 줌

ơ

: :

뭉

중 -

So

: $v$

3. 남

हैं

y 0

ㄷํㅇ

명

कै*

(1)

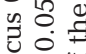

의

의

is

.

啳

त :

ปี

శृ

ป

곡뎡

공.

ठํ वे

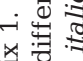

ㅋ.

류

选 d

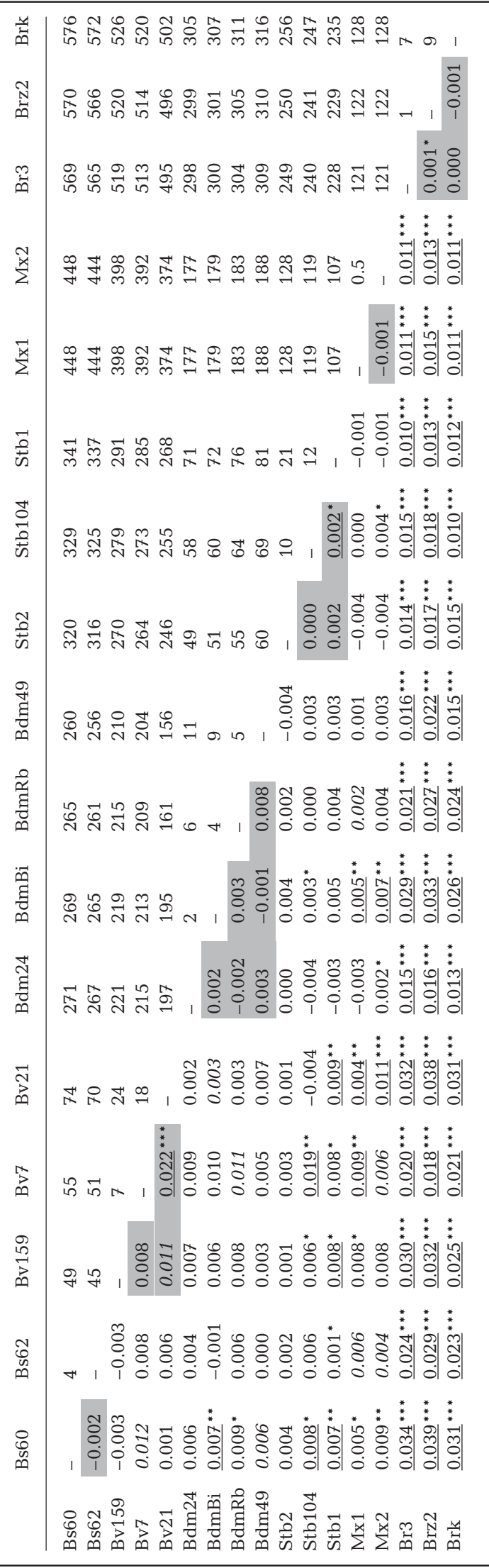

